\title{
Speaking Practice Reform and the Teaching Model of Chinese Course for Xinjiang Minority Preparatory College Students in Mainland China
}

\author{
Yanyan $\mathrm{Pi}^{1, \text { a }}$ \\ ${ }^{1}$ Nanchang Institute of Science \& Technology, Nanchang, Jiangxi, 330108
}

\begin{abstract}
Keywords: Minority Matriculation Students; Chinese Language Training Curriculum Reform; Teaching Model
\end{abstract}

\begin{abstract}
In order to realize the goal of prosperous and prosperous democracy in our country, it is necessary to combine the culture of the fifty - six nationalities in our country and accelerate the construction of ethnic minority areas in the mainland. Preparatory education is the main component of higher education in minority areas of our country, and the quality of Chinese teaching in minority students affects the improvement of Chinese proficiency and comprehensive ability of minority students. In recent years, ethnic minority students in colleges and universities have become more and more concerned with oral Chinese teaching, and few students participate in minor Chinese courses. For minority students, the level of mastery of Chinese spoken language will always be accompanied by their learning and living around, so the preparatory education should be spoken language teaching as the most important part of Chinese teaching. At present, it is very practical to study the reform of Chinese oral training course for ethnic minority matriculation students. This paper expounds the problems encountered in the study of the current situation of Chinese spoken language from the minority pre-college students and the reform of Chinese oral training courses.
\end{abstract}

\section{Introduction}

Language is what people say when they communicate, not words written on paper. Language as the most important communication tool in society, it plays an important role in human daily life. With the rapid development of China's economy, the society for ethnic minority students Chinese language requirements is also increasing [1]. Nowadays, the Chinese language teaching of minority colleges and universities in our country has been developed. However, we can not ignore the problems that still exist. The ultimate goal of the preparatory Chinese teaching is to promote the ability of the minority students to listen, speak, read and write four aspects. Only by fully mastering Chinese knowledge can the next learning The In the context of the rapid development of society and the urgent need of talents, how to improve the ability of Chinese language students to become a college and society needs to be concerned about.

\section{The Status Quo of Minority Students Studying Chinese Spoken Language}

At present, China's ethnic minority Chinese teaching has been effectively popularized, supported by the state funds have also made good development, with a certain degree of education experience and teaching accumulation. With the growth of China's ethnic minority economy, the scale of Chinese teaching gradually expanded, the teaching level also mentioned the effective promotion. But Chinese teaching still has some problems. Respectively, the following aspects:

As a minority student whose mother tongue is not Chinese, it takes more time for them to learn Chinese. In the present situation, when teachers are taught Chinese language students for ethnic minority students, they are almost individual dictatorships. Teachers lack the interaction with students and do not have a good relationship with students. Insist on teachers, leading students to the Chinese language classes are full of tension. Some teachers on ethnic minority students with discrimination, in the teaching process of export wounding, seriously damaged the image of teachers also allow minority students to learn Chinese language lost confidence [2].

The teachers who teach Chinese oral knowledge are lacking the consciousness of advancing with the times in teaching methods. For teachers, teachers are asked to ask the teacher. The teacher will 
ask the students to answer the model. There is no good use of electronic computer equipment to add color to teaching. In the past, students are more likely to be interested in spoken Chinese, not to mention that students are able to master Chinese spoken language.

At present, the teaching goal of Chinese spoken language teaching has greatly neglected the existing knowledge level of minority students and can not help in the students' actual life. Many of the preparation of spoken Chinese textbooks are only fixed on the basic grammar, practicality is not strong, can not meet the daily needs of students, so as to enhance the level of students did not play a substantive role. Teachers also did not participate in the process of learning students to participate in the guidance, resulting in many ethnic minority students in the use of Chinese to communicate, poor expression, oral communication level obvious loopholes.

\section{The Difficulties Encountered in the Reform of Chinese Oral Training Courses}

Nowadays, the teaching materials of Chinese language teaching in the Xinjiang ethnic minority colleges and universities are basically formulated according to the teaching materials of Chinese language and culture in Beijing. These materials are difficult to form with the students 'system of junior high school teaching materials, and the students' actual life It is difficult to build a bridge. To the national Han test as a matriculation of the standard, there are many students and teachers on the Han test should be completed the specific content is not clear. So in the teaching process, the content of the teaching should be involved in the vague, almost based on teaching materials, teaching materials on what to teach what. Sometimes because of the type of confusion, resulting in the emergence of difficult words and grammatical point of the order of the reverse of the phenomenon, and thus can not achieve the goal of teachers.

China has also invested a lot of money in education, and actively encourage colleges and universities to buy multimedia equipment. But for the mainland colleges and universities Xinjiang ethnic minority preparatory classes, the progress of information technology is still too slow. Before and after the implementation of the national Han test, the mainland college preparatory teachers did not make the corresponding changes in the intensity of multimedia-assisted teaching, although the escape has been relying on chalk and mouth teaching methods, but still only stay in the use of tape recorders and television and other electrical Equipment, auxiliary teaching, the number of multimedia classrooms are not many, and the use rate is not high.

Nowadays, the after-school activities of the Tibet Autonomous Prefecture Minority Preparatory Course are mostly composed of some Chinese contests, which are basically carried out around Chinese oral expression and writing Chinese characters. There is a lack of universal recognition of the students selected for this activity. And in order not to affect the national Han test, after school activities are basically concentrated in the examination, the time is tight, more activities, some activities inevitably flow in the form, the effectiveness is not high.

Preparatory Chinese classroom teaching time is extremely limited, the class under the active preview and review and listen to the classroom teaching effect is played a very important role. However, according to the survey results show that there are nearly $50 \%$ of the students are limited to classroom lectures, classes to complete the work of learning habits, the content is only the mechanical repetition and awareness, and finally through the rote The way to complete the examination, will not live and use, flexible [3]. In addition, there are still a small number of teachers in colleges and universities are still using the traditional inculcation of teaching, students in a passive acceptance of the status. And because of the class time each lesson, teaching tasks heavy, many times only on the book books, can not do too much to add and expand, which led to students interest in class, affecting the teaching effect.

\section{Speed up the Process of Chinese Language Reform Measures}

The teaching materials chosen by Chinese ethnic groups in Xinjiang Autonomous Region are not helpful to students' professional learning. Based on this, I hope that China's Education Department can combine the relevant experts, with rich teaching experience of Chinese spoken language 
teachers, according to the characteristics of minority students in colleges and universities, including some language skills, including training, but also with the professional knowledge article. You can also choose some of the Han culture of knowledge included in the preparation of its shortcore Chinese professional teaching materials, so that the contents of the local students and the future professional learning content of the convergence of each other, so as to avoid unnecessary repetition of teaching and to prevent students beyond the ability The "cross" teaching, and truly meet the students for the follow-up professional learning and employment lay a solid foundation of Chinese goals.

In recent years, although some colleges and universities in the multimedia classroom has been established for many years, but compared with other disciplines, colleges and universities of Chinese teaching information hardware facilities are relatively backward. Therefore, we should focus on strengthening the construction and management of the teaching network in colleges and universities, and increase the breadth and depth of the application of information technology in the preparatory Chinese education so that the educational resources of colleges and universities can form the most reasonable configuration as soon as possible [4].

To play the spirit of self-practice of college students, to class as a unit, once or twice a month, the use of self-study time, organized by the students responsible for the formation of some Chinese language practice class second classroom activities, teachers only need to guide and supervise The To maximize the excitement of students' interest in learning, so that they are in the activities of secondary school, in the fun of secondary school, really change the passive learning to take the initiative to learn, so as to achieve the improvement of learning efficiency, to achieve the best teaching results.

In the design of classroom teaching and the cultivation of students' self - learning ability, the course should be used as a resource to strengthen the connection between curriculum content and students' life, modern society and scientific development on the basis of students' interest in learning and experience. In the actual teaching, according to the psychological, cultural and cognitive characteristics of the minority students in Xinjiang and the status quo of the Chinese knowledge structure, the existing textbooks are appropriately withered and supplemented, and the systematic and progressive nature of the text knowledge is emphasized. Carefully designed every lesson plan, so that strive to individual lesson preparation, including the introduction of novel new courses, design problems, vivid, humorous language, intuitive image teaching, practical practice and cooperation and exchange, timely recognition and encouragement Wait. Pay attention to the students' learning methods of counseling and self-learning habits of training, students need to develop each pre-class preview, after-school review of good habits. At the same time to guide students under the use of books, television, radio, computer networks and other means to widely collect, learn and text related to higher information in order to lay the foundation for students to study lifelong.

\section{Conclusion}

To sum up, colleges and universities should fully understand the importance of minority Chinese teaching reform, according to the teaching objectives of teaching materials, and actively promote the college Chinese teaching information process, to carry out effective after-school activities, and fully stimulate students' interest in learning and strive to cultivate the students' self-learning ability in several aspects of the reform of minority Chinese teaching, so as to promote the Xinjiang ethnic minority college students in the level of Chinese students have a qualitative leap, but also for China's further development and lay a good foundation.

\section{References}

[1] Ma Zhonghua, Li Yanping. Analysis of the Compilation of Professional Chinese Textbooks - A Study on the Chinese Teaching of Ethnic Minority Preparatory Course in Xinjiang Colleges and Universities [J]. Journal of Taiyuan Urban Vocational College, 2013, 11: 126-127. 
[2] Yang Wenge. Chinese study on the current situation of Chinese learning and Chinese language application of Xinjiang Minority College students - Taking Xinjiang Agricultural University as an example [J]. Journal of Xinjiang Vocational University, 2013, 06: 58-62.

[3] Ren Shuyuan. MHK examination- the national college students in Chinese teaching aids - to Ningxia University College of national preparatory education as an example [J]. Journal of Jiamusi Education Institute, 2012, 12: 165-166.

[4] Pu Xiaohua. Discussion on the reform of Chinese teaching of minority students in Xinjiang universities [J]. Contemporary Education Practice and Teaching Research, 2016 (03) 